\title{
Lexico-grammatical peculiarities of adverb as a part of speech in Turkic languages
}

\author{
Yerbolat Saurykov \\ Taraz University of Innovations and Humanities, Taraz, Kazakhstan \\ Email address: \\ e_saurykov@mail.ru
}

\section{To cite this article:}

Yerbolat Saurykov. Lexico-Grammatical Peculiarities of Adverb as a Part of Speech in Turkic Languages. International Journal of Language and Linguistics. Vol. 2, No. 6, 2014, pp. 356-360. doi: 10.11648/j.ijl1.20140206.13

\begin{abstract}
The article deals with the problems of etymology, development and formation of the adverb as a part of speech in a system of the Turkic languages. The paper presents a detailed analysis of lexico-semantic properties and morphological peculiarities of adverbs in some separate Turkic languages. The author carried out a thorough exploration of research works of many distinguished scholars of Turkic linguistics concerning a development of adverbs as a linguistic phenomenon from the ancient Turkic epoch up to the present time. In the process of investigation the author revealed their scientific viewpoints and hypotheses, compared and generalized them.
\end{abstract}

Keywords: The Adverbs, the Formation of Adverbs, Lexico-Grammatical Peculiarities, the System of the Turkic Languages

\section{Introduction}

Every word in language has some definite meaning and its name. All objects and phenomena are denoted by means of words and their meanings and concepts become fixed in a language.

If there is neither a thing or phenomenon nor the concepts by which they are denoted, there won't be words as a linguistic reflection of the real, material world. Objects and phenomena are able to exist independently from words in a language, however they are named, that is, they are verbalized with the help of words, which express meanings and notions of the objects and phenomenon of the world surrounded. Namely, the meanings, expressed by words, are fixed in a linguistic consciousness of language speakers. In order that a word may denote (name) something, as a necessary condition should be its material form consisting of sound combinations. Such a tight unity and mutual stipulation of words, objects or phenomenon appeared long before the formation of the written language system, since ancient times under conditions of kin - tribal relations. In other words it came into being in an oral speech of people of the primeval society, where a use of a definite group of words associated by meaning represented a natural phenomenon inherent for all languages.

\section{Main Part}

During a centuries-old historical development of a language its word-stock and grammatical structure could not remain without changes. The lexical and grammatical nature of words undergoes various transformations, stipulated by evolutional processes of the language development. The words in a language are analyzed, classified and go on developing depending upon the peculiarities of their use and performing function. Thus, in the process of their development and formation the words are being grouped by various features, that is, from grammatical point of view they become discriminated into parts of speech.

Each of these parts of speech acquires its own common, categorial meaning. The groups of words combine according to their grammatical features, and then they are formalized on the ground of some morphological indications, acquiring by that special word-building and word-changing forms. Being formed as a part of speech the group of words undergoes its long historical development and a process of formation, with that, being subjected to various alterations of the formal features and indications during the whole evolution of the language. The parts of speech are lexico-grammatical groups of words which differ from each other by a common categorial meaning and properties as well.

When the group of words is considered as a part of speech, primarily there should be taken for a basis the meanings 
designated by the words, as: substantive, attributive, processual and root. In our view such meanings shouldn't be further subdivided into lexical and grammatical, on the contrary, they should be generalized and recognized as a general categorical meaning which is rightly considered to be one of the main features in the parts of speech differentiation.

The formation of adverbs as a part of speech serves as an obvious illustration of the fact, that in the course of the historical development of a language the parts of speech don't emerge at a moment, but they are forming successively and gradually. Many scholars adhere to the opinion that in the Indo-European languages the formation of adverbs was a result of using the case endings of nouns and pronouns in the function of adverbial modifier in the sentence. Meanwhile, such adverbs functioning in modern Turkic languages as бipze, зорга, жовары, ілгері (together, hardly, ир, forward) some time ago belonged to the definite group of words and were used in the functions inherent of the other parts of speech.

A number of such words by their application and functions performed in the sentence have been firmly established in a role of adverbial modifier. Later on, in connection with a shift of the semantic coloring of the words, a word primarily having had a concrete meaning acquires an abstract and general character. In case when the word "absorbs" peculiarities and properties of an adverb as an unchangeable part of speech it passes to another system.

The expression of meanings of an adverbial modifier in words is a result of inner lingual processes when the roots of words come into grammatical relations with the case forms and affixes of deeprichastie. The words inherent of other parts of speech in a result of their frequent use in a certain case endings gradually lose their original meaning, acquiring by that other meanings; with this, some endings, attached to them become an integral and inseparable part of these words.

The words having got obsolete in a formal sense and growing apart their initial roots (that is origin) in a semantic meaning detach from the group of words to which they earlier belonged (for instance, from nouns, adjectives, pronouns, numerals and verbs) and go to the groups of words different in their lexical content.

Alongside, they are converted into the words which in a formal sense are not declined at all, or change partly when taking single case endings. Such words in a semantic meaning express different states and signs of action and as a rule, they do not possess any material meaning and mainly perform the function of an adverbial modifier in the sentence. From the point of view of lexico-semantic and morphological peculiarities they refer to the adverbs.

If we look upon affixes in a composition of some adverbs in the Turkic languages from the point of view of their origin and despite the fact, that they primarily were endings, in the contemporary language it is impossible to detach them from a root of the word. In other words they "have grown together" with the root and become its component (in the history of language this process is called growing together). As a result of such various phenomenon and inner lingual processes adverbs were built up.
Many research works published in different times dealt with the peculiar features of the adverb as a part of speech, its semantics and lexico-grammatical characteristics. The works also carried out a thorough analysis and described the main processes in the formation of adverbs and also the means of word-building. By their composition adverbs were subdivided into root and derivative. The scholars also analyzed the main properties intrinsic of each of the adverbial words as well as their role in a sentence. Besides, they revealed such groups of words as polysemantic adverbial words and the words which only under influence of a strong syntactical link within the sentence distinguished themselves in the meaning of an adverb. Despite that adverbs were an object of scientific concern of many linguists, up to date the scholars exploring the Turkic languages haven't come to common opinion on a lingual nature of adverbs and their scientific premises and hypothesis haven't developed into the united system. In our view the reason of it is that the scholars haven't differentiated between the adverbial words and the words which within the sentence have an adverbial meaning or its shade.

On the whole, up till now there have remained open and without complete study some problems of theoretical comprehension of the adverb as a part of speech, its adequate definition and some processes in word-building of adverbs as well.

For the last years the scholars of Turkic linguistics undertook a detailed analysis of a theoretical definition of the adverb as a part of speech and advanced a number of scientific thesis and sound hypotheses. Adverbs as an object of the scientific research have been explored from different aspects; the investigations resulted in revealing their particularities and common quality. Among those labors the following are of the special significance: A.Iskakov "Adverbs in the Modern Kazakh Language" (1950), S.F. Fuzaylov "Adverbs in the Modern Uzbek Language" (1953), S.A.Davletov “Adverbs in the Modern Kyrgyz Language" (1956), Kh. Gafurova "Adverbs in the Modern Turkmen Language" (1959), A. Shuckyurov "Adverbs in the Azerbaijan Language" (1966), Z.Z. Absalyamov "Adverbs in the Modern Bashkort Language" (1975), A.G. Guliev "Adverbs in Turkic Languages of the South-Western group" (1983), "Adverbs in the Modern Kumyk Language“ (1987).

The linguists carry on a profound and detailed study of the problems of etymology, development and formation of the adverb as a part of speech, its distinctive features as a separate group of words, its connections with other parts of speech and also the main word-building means and the process of origin.

Professor A. Iskakov considering the adverbs in the system of the modern Kazakh Language as a separate and independent category carried out their thorough analysis and before drawing his conclusions on a lingual nature of adverbs he appealed to the history of exploration of such words. Generalizing the theories of the linguists on etymology and functioning of the adverbs and their grammatical peculiar features A. Iskakov supports the views of the linguistspredecessors. The scholar carried on his investigation, then compared the obtained results with other substantiated 
hypothesis and as a result he introduced new scientific ideas, the study of which enabled him to draw his own conclusions. The researcher attached great importance to the investigation of the semantic groups of the adverbial words. Supporting viewpoints of the other scholars on the classification of adverbs, he subdivided them into several groups and defined a sphere of employment of each of them. Along with that, A. Iskakov carried out an analysis of lexico-grammatical characteristics of adverbs and revealed their lingual nature.

In the process of working out the investigation the author also paid attention to the peculiarities of the formation of some adverbs. From the point of view of history of the language he subjected to analysis some ways of formation of separate adverbs, revealed and described a few ways characteristic of the formation of adverbial words (Iskakov 1950).

Each separate part of speech has its origin, formation and individual development. The adverb being a subject of our investigation earlier belonged to that part of speech the lexico-grammatical properties and semantic peculiarities of which were not yet defined. The language was gradually developing and along with it its entire system was forming, which is rightly considered to be its basis and main source. The unique cultural legacy embracing the history of all Turkic languages is represented in Orkhon -Yenisey and Talas written monuments which are regarded as a sample of the written speech. These monuments were fairly adapted to the lingual system of that epoch and known as a system reflecting a certain lingual norm. While defining a nature of each part of speech, its lexico-grammatical properties, a way of formation and stages of the development it is rationally to rely on the facts of Old Turkic.

In the opinion of Professor V.M.Nasilov, a researcher of Old Turkic the adverbs in the V-VIII c. were not yet formed as an independent part of speech and they were in the process of their development (Nasilov 1960: 39). The assumptions that the adverbial words were rarely encountered in the language of the Yenisey monuments and moreover that the origin and formation of some adverbs up to now have still remained as an uncompleted process were given by the philologists of Turkic linguistics I.A. Batmanov, Z.B.Aragachi, G.F.Babushkin (Batmanov, Aragachi, Babushkin 1962).

In investigations of the language of the medieval written monuments it may be observed a significant enrichment and increase in number of the adverbial words as well as widening of the sphere of their use and functions.

Particularly in that epoch the formation of adverbs as a separate group of words was taking place, the adverbs in some degree were systematized depending on a way of their formation. The scholars studied an emergence and development of adverbs in the process of their formation as an independent part of speech, their relations with other parts of speech as well as their lexico-grammatical and semantic peculiarities. The assumptions and scientific evidences of a lingual nature of adverbs were widely discussed in academic philological sets.

Let us dwell upon the definitions, characterizing the adverb as a part of speech in separate Turkic languages and either upon the description of a lexico-grammatical nature of these words.

In the opinion of the Bashkort language researchers the adverbs in Modern Bashkort as a part of speech are regarded as a grammatical category, having its individual lexical and grammatical peculiarities. In our view it is necessary to make precise a notion of nature of the grammatical category. Should or shouldn't we refer adverbs to the grammatical category? What premises are necessary in order that a definite part of speech represents a grammatical category?

The linguists studying a structure of the language and its nature up to the present time have adhered to the opinion that adverbs like other parts of speech are an independent grammatical category. However, taking into consideration the recent scientific views they state that adverbs cannot be a grammatical category. The views of that kind are evidentially and clearly revealed in the science investigation of S.Isaev "Grammatical Characteristics of Words in Modern Kazakh" "... in all parts of speech of the language there cannot be the same grammatical categories. It is possible, that some parts of speech (for instance, numerals, pronouns, adverbs etc.) cannot have any grammatical category at all, since these are words which never change according to the definite paradigmatic system neither they have grammatical, formal kinds" (Isaev 1998: 61).

The above mentioned linguistic facts entirely correspond to the nature of adverbs that is why referring them as a part of speech to the grammatical category will be accepted as ignoring the recent scientific achievements. Let us turn to the standpoint of the Bashkort language philologists mentioned above. They assume that adverbs by their semantics and structure reveal the largest closeness to adjectives (Yuldashev 1981: 197). Indeed, these two parts of speech by their grammatical characteristics are very alike. The essential feature distinguishing and differentiating them is that the adjective expresses a property and quality of an object, and as for the adverb, it points out some characteristic features of an action, rarely that of a quality of an object. In some examples there may be observed a phenomenon when the adverb in the Bashkort language in attributive relations is placed before a noun and expresses a feature of an object. However, not all adverbs may be used in such attributive function.

Let us dwell on A.N.Kononov's viewpoint concerning a nature of adverbs. The scholar presumes that in the Uzbek language adverbs define different features of an action (motion) and a degree of its performing. Their major morphological-syntactic characteristic feature is their unchangeability and the principal lexico-morphological peculiarity consists in their property to come into relations with all changeable words.

Supporting the linguist's opinion S.Fuzaylov in his candidate thesis regarding the adverbs recognizes a formality in treating an adverb as a part of speech in the Uzbek language both from semantic and syntactical points of view. In his opinion adverbs owing to their peculiarities and qualities as a grammatical phenomenon do not have their full characteristics (Fuzajlov 1953: 3-6). Just because of it an attempt to 
differentiate adverbs from other parts of speech more often becomes complex. One of the properties of adverbs in this language is their changeability or unchangeability (in some separate forms).

As for their morphological quality they differ from other parts of speech by grammatical indications. In fact, the assumption that in the Uzbek language a formation of adverbial words has not been over yet seems ambiguous.

Whatever Turkic language we take a predominant part of the adverbs in its word stock and content has precise, peculiar and part-of-speech properties and qualities, by this reason they are considered to be quite formed words.

The authors of the history of grammar of the Bashkort language A.M.Aznabayev and V.Ch. Psyanchin on the basis of investigation of some scholars' views concerning a general nature of adverbs and their classification give the following definition of them: "The adverb is an independent and unchangeable part of speech, indicating some characteristic features of an action or a quality of an object" (Aznabaev, Psjanchin 1983: 224).

The adverbs in the Modern Turkic languages represent a completely formed independent part of speech. Researcher I.I.Meshyaninov mentions that in the formation of adverbs a special role is given to the members of the sentence and namely, to the adverbial modifier words, he also brings out in what way their gradual and stage by stage formation occurs (Meshhaninov 1978: 341).

No doubt, that the part of speech formation of adverbs was affected by different parts of speech. The adverbs separated from other words depending on their employment within the sentence. However, a transition of all adverbial modifiers into class of adverbs is not an indispensable condition. Adverbs as a lexical group of words owing to their grammatical form separated from other parts of speech but with this, not being used as a verb. The transition of adverbs into other parts of speech and their ability to accept properties of a second grammatical category finds its reflection in the true facts of many monuments of the ancient Turkic writing as well in the contemporary Turkic languages.

The adverbs are one of the parts of speech, constituting a number of unchangeable words in the Turkic languages. As for their unchangeability up to the present there has been no single compromise opinion on it among the scholars.

I.I.Meshyaninov writes about unchangeability of the adverbs and their non-acceptance of word- changing forms: «These case endings are fixed on some adverbs, giving them different meanings and being converted into unchangeable formants in each individual case.

In this way i.e. by different case alterations it is possible to make up a number of adverbs from one stem. Such case alteration is not at all an inclination of adverbs. It was the case alteration in the past when the adverb was not the adverb yet, it used to be a usual inclining form in a syntactical meaning of the adverbial modifier. But when the case forms fixed on the adverb they turned into its formant, having lost a significance of the case ending. In this way in the Russian language there appeared a number of adverbs of case and case-prepositional formation out of one stem, compare: верхом, наверху, сверху и.т.д.» (on (horseback), above, from above etc. ) (Meshhaninov 1978).

It is known that adverbs move from other parts of speech, loosing with that their original concrete meaning, then they acquire a common, abstract meaning and being an unchangeable part come into grammatical relations with all changeable words.

The investigation of a lexico-grammatical nature of adverbs as a part of speech in the Turkic languages from the general historical point of view and turning to the works of some scholars with the purpose of generalization of scientific definitions of adverbs will allow to systemize their common properties and distinctive features.

The similar systematization of methodological premises will help define the stages of development of also other words in the Turkic languages, to find out and reveal their common lexico-grammatical characteristics, which in turn will influence a formation of a certain system of study of the adverb as a linguistic phenomenon.

In the course of comparative and successive investigation it is revealed that in the ancient Turkic epoch an adverb as a part of speech was not fully formed. Only in the medieval Turkic epoch adverbial words began to separate from other words and having formed as an independent part of speech and individual grammatical phenomenon they began acquiring some lexico-semantic and grammatical properties.

The results of the scholars' investigation display that adverbial words as a member of the sentence perform the function of an adverbial modifier, actually, adverbs were formed as an independent part of speech in a result of such processes.

In the course of the comparative research of the factual data of the modern Turkic languages it now appears, that in separate Turkic languages adverbs as a part of speech were not only firmly established in the linguistic system, but, moreover they strengthened their positions, separating from other groups of words by their individual qualities and widening their lexico-semantic groups, all these facts characterize a rapid development of word-making possibilities of adverbs.

As it has been already said adverbs are an unchangeable part of speech and they denote a property of an action and a quality of an object. However, adverbial words can express properties of an action only by means of verbs and adjectives. Adverbs in the languages were derived from words belonging to different parts of speech and by the time when the adverbs became an independent part of speech they were classified on the basis of a common categorial meaning of the words, referring to this or that group. It means that the division into kinds and types took place in dependence of the expression of different qualities of actions and a quality of a substance by the adverbial words.

\section{Conclusion}

The expression of the properties of an action in the language is realized both by means of separate forms of some nominal words and with the help of some forms of the verb. But the 
adverbs have a special semantic distinction which allows moving away and separating from them. On condition that the nouns and verbs with their potential possibilities express a property of an action and quality of an object, their meanings will be as homogeneous and related as a long-standing, concrete meaning of the word.

On the contrary, the meanings of the words will be used in such a way as if they lost their long-standing concreteness and having got abstractive they became to express a generalized and vague meaning.

\section{References}

[1] AZNABAYEV, A.M., PSJANCHIN V.Sh. (1983). Istoricheskaja grammatika bashkirskogo jazyka. Ufa: Izd-vo BashGU.

[2] BATMANOV, I.A., ARAGACHI Z.B., BABUSHKIN G.F. (1962). Sovremennaja i Drevnjaja enisejka. Frunze: Izd-vo AN Kirg. SSR.
[3] FUZAJLOV, S. (1953). Narechie v sovremennom uzbekskom jazyke. Avtoreferat dissertacii k. filol. n. Moskva.

[4] ISAEV, S. (1998). Kazirgi kazak tilindegi sozderdin grammatikalyk sipaty. Almaty: Rauan.

[5] ISKAKOV, A.I. (1950). Narechie v sovremennom Kazahskom jazyke. Almaty: Izd-vo AN Kaz SSR.

[6] KONONOV, A.N. (1960). Grammatika sovremennogo uzbekskogo literaturnogo jazyka. Moskva-Leningrad: Izd-vo AN SSSR.

[7] MESHHANINOV, I.I. (1978). Chleny predlozhenija i chasti rechi. Leningrad: Nauka.

[8] NASILOV, V.M. (1960). Jazyk Orhono-Enisejskih pamjatnikov. Moskva: Izd-vo vost. lit.

[9] YULDASHEV, A.A. (1981). Grammatika sovremennogo Bashkirskogo literaturnogo jazyka. Moskva: Nauka. 